\title{
Water-energy-food nexus perspective: Pathway for Sustainable Development Goals (SDGs) to country action in India
} \author{
Pham Thi Mai Thao ${ }^{d}$ \\ a Institute for Global Environmental Strategies (IGES), Hayama, Japan \\ $b$ Central University of Rajasthan (CURAJ), Bandarsindri, India \\ c Bangladesh University of Engineering and Technology (BUET), Dhaka, Bangladesh \\ d Hanoi University of Natural Resources and Environment, Hanoi, Viet Nam \\ * Corresponding author. Email: b-mitra@iges.or.jp
}

Bijon Kumer Mitra ${ }^{\text {a }}$, Devesh Sharma ${ }^{\text {, }}$, Tetsuo Kuyama a, Bao Ngoc Pham a , G. M. Tarekul Islam c, and

\section{ABSTRACT}

Water, energy and food securities lie at the heart of the Sustainable Development Goals (SDGs). Since these securities are interconnected, the business-as-usual approach (sectoral approach) cannot achieve them and need to apply the water-energy-food nexus approach for identifying and overcoming the roots of barriers and challenges. The study aims to prioritize interlinkages between SDG-2 (food security), SDG-6 (water security) and SDG-7 (energy security) for country action. In order to achieve this aim, the study implements a set of methods including stakeholder perception survey, network analysis, regression analysis and cross-sectorial group discussion. This article summarizes the outcomes of a case study in India. Stakeholders cognition derived through scrutinizing the perception survey admitted the need for a nexus approach in the action plans towards the SDGs. Quantitative assessment of interdependency showed that, of 182 interlinkages between SDG-2, SDG-6 and SDG-7 targets, 124 interlinkages had synergistic relation. The combined outcome of the cross-sectorial group discussion identified eight interlinkages as high priority $(p>0.9)$ for immediate integrated planning and action. A total of ten interactions are moderate ( $\mathrm{p}=0.6$ to 0.9$)$ and eight are low priority interlinkages $(\mathrm{p}<0.6)$. Solid understanding of synergies and trade-offs associated with SDG targets and initial prioritization of interlinkages would help India reorient its SDG priorities from a water-energy-food nexus perspective.

\section{KEYWORDS}

Country actions, India, Sustainable Development Goals, Water-Energy-Food Nexus

\section{DOI}

https://doi.org/10.30852/sb.2020.1067

\section{DATES}

Received: 5 December 2019

Published (online): 13 July 2020

Published (PDF): 19 November 2020

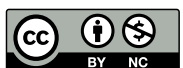

This work is licensed under a Creative Commons Attribution-NonCommercial 4.0 International License.

\section{HIGHLIGHTS}

» Key stakeholders of India have a high level of perception about the interdependency of SDG-2, SDG-6 and SDG-7.

» Out of 182 interlinkages, 124 showed a synergistic relationship, implying that there is a high potential to capture synergies by taking a nexus approach in SDG implementation that can provide effective resource solutions and contribute to swiftly achieving three key SDGs.

» A case study in India identified nine priority targets: T2.1, T2.2, T2.4, T6.1, T6.2, T6.3, T7.1, T7.2 and T7.3. Among interactions between these nine targets, eight interlinkages are identified as high priority ( $p>0.9$ ) for immediate integrated planning and action. A total of ten interactions are moderate ( $p=0.6$ to 0.9 ) and eight are low priority $(\mathrm{p}<0.6)$. 


\section{INTRODUCTION}

Water, energy and food are the basic needs for all human beings and the fundamental elements necessary for economic growth and development. Despite significant progress, the security of water, energy and food supplies each remain far from being achieved. Notably, in the Asia-Pacific region, millions of people lack basic services (water, energy and food), are deprived of their human rights and are trapped in poverty. About 280 million people lack adequate access to safe water (World Bank, 2018), more than half of the population suffer food insecurity (FAO, IFAD, UNICEF, WFP, \& WHO, 2019) and 350 million lack access to electricity (IEA, 2018). It is projected that demand for these three resources will further increase in coming years and meeting such additional demand will be challenging under the conventional uni-sectorial approach. It is envisaged that by $2030,30 \%$ of the world will be faced with water shortage (WWAP, 2015), food demand will increase by $50 \%$ (FAO, IFAD, UNICEF, WFP, \& WHO, 2017) and energy consumption will increase by $30 \%$ (IEA, 2017). With Asia and the Pacific taking a leading role in terms of economy and development, the continuing growth in population will place immense pressure on these resources, which will lead to increasing conflict.

The role of food, water and energy are justifiably accorded critical status in the approved Sustainable Development Goals (SDGs) as they are crucial for sustainable development, and specific goals and targets have been set for these three key sectors. Water, energy and food are not isolated but are inextricably linked. Concerns expressed in the literature emphasize the relevance of water, energy and food linkages not only for poor people who have limited access to water, energy and food of insufficient quality but also for fast-developing regions with a rapidly growing demand for these three elements (Bazilian et al., 2012; Hoff, 2011; ICIMOD, 2015; Waughray \& Workman, 2011). Going forward, ignoring this interdependency will only create further contradictions and lead us away from the bedrock principle of sustainable development (Merrey, 2015). A water-energy-food nexus provides a basis which can be considered inevitable in the implementation of the SDGs (Salam, Pandey, Shrestha, \& Anal, 2017; Rasul \& Sharma, 2016; Gallagher et al., 2016).

The most important challenge is how global ambition should be interpreted at the national level. Hence, the Open Working Group for the SDGs emphasized setting up national targets, taking into account the national context such that these targets can be elaborated with indicators. The water-energy-food nexus approach is compatible with this principle and will help identify suitable sets of actions for specific countries (or regions) (Weitz, Nilsson, Huber-Lee, Davis, \& Hoff, 2014). The ultimate aim of the water-energy-food nexus approach is to maximize synergies through strengthening cross-sectoral integration, which leads to an upgrade of resource management to enhance water energy and food security (Scott, Crootof, \& Kelly-Richards, 2016). To date, much discussion has taken place at international and regional levels but has mostly dealt with issues at the conceptual level. In most cases, policy and development choices are made on a unilateral basis, and the lack of knowledge on water-energy-food nexus has often led to mismatches in prioritization and decision-making, which will hinder sustainable development. Asia and the Pacific SDGs progress report 2019 reported that the region could not make sufficient progress to achieve resource-related SDGs, thus greater efforts are needed (UNESCAP, 2019).

Funded by the Asia-Pacific Network for Global Change Research (APN), we conducted this study in three emerging countries of Asia including Bangladesh, India and Viet Nam to identify priority SDG targets and understand interlinkages between SDG-2 (food security), SDG-6 (water security) and SDG-7 (energy security). Finally, the study attempted to identify priority interlinkages between targets for integrated action that would guide SDG implementers to design action effectively and meet the related targets swiftly. This article will focus on India as a case study. For the other two case studies, please refer to the full research report (Kuyama et al., 2019).

\section{METHODOLOGY}

To meet the objectives of this research, the study team relied on several methods such as stakeholder survey, networking analysis, regression analysis and cross-sectoral group discussions.

\subsection{Stakeholder perception and network analysis}

A questionnaire survey was conducted, targeting all relevant ministries and governmental departments, NGOs, academia related to water, food and energy, to analyse stakeholder perception on the importance of nexus aspects for the country actions on SDG-2, SDG-6 and SDG-7. The first part of the questionnaire sought perception of stakeholders on the interdependency of SDGs and targets on "No hunger", "Clean water and sanitation" and "Energy security" goals and targets. This was followed by part-2 related to country's readiness to implement a nexus approach in country actions. Responses of the questionnaire were quantified by converting the response in terms of quantitative value. The following quantification was used for various responses 
to prepare network maps. The value assigned to the strong opinion is 3.0 , moderate opinion is 2.0 , weak opinion is 1.0, and for no link, it is 0 . Then, the weighted average was taken to link each of the three SDGs with targets of the remaining two SDGs. This was followed by a network analysis using Social Network Visualizer (SocNetV) software to visualize relationships between SDG-2, SDG-6, SDG-7 and its relevant targets. SocNeV is freely available at https://socnetv.org/downloads.

\subsection{Quantitative assessment of interlinkages among the SDG targets on water, energy and food security}

Quantitative aspects of the interlinkages are addressed by using statistical techniques to test hypotheses on possible associations among indicators of water, food and energy goals. Results of this analysis are important in determining whether and to what extent one indicator quantitatively correlates with the others. The identified linkages between the targets have been validated using Pearson's correlation coefficients and were obtained through pairwise comparison of those indicators with their statistical significance. For time series (from 2000 to 2015) regression, relevant data were collected from various sources as mentioned in Kuyama et al. (2019). The linkages among SDG-2, SDG-6 and SDG-7 were analysed through pairwise correlation

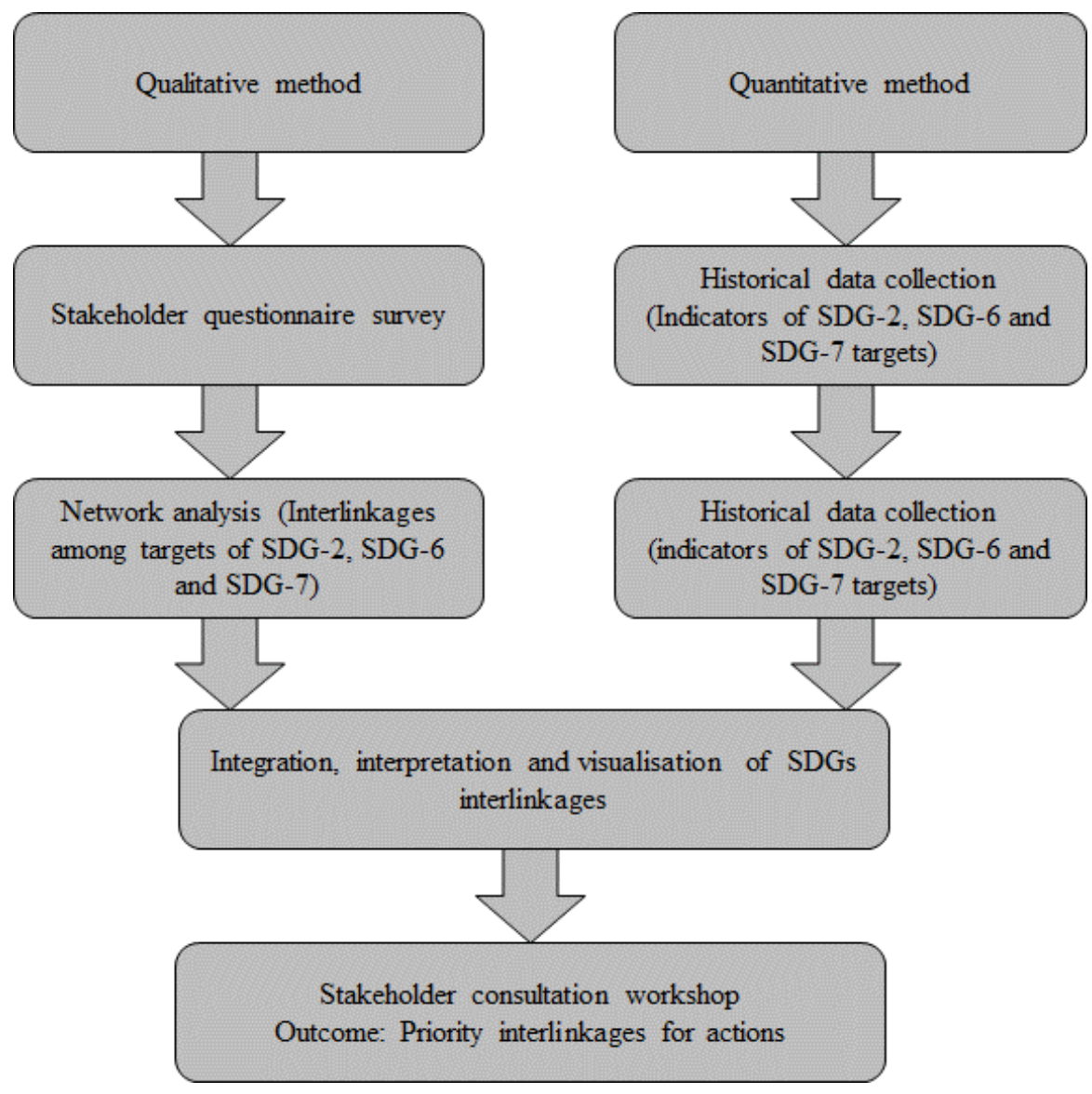

FIGURE 1. Methodological framework of the study. among the indicators which measured these targets. This pairwise correlation describes the direction of linkages between the two variables. Pearson's correlation provides a measure to evaluate the strength of an association between two variables. Pearson's correlation analysis can capture nonlinear correlations between variables and is less sensitive to outliers (Hauke \& Kossowski, 2011). In Pearson's correlation, a p-value of less than 0.05 is considered as statistically significant. In this study, a p-value greater than 0.6 is considered to indicate a synergy (positive association) between two indicators, a p-value less than -0.6 is considered to indicate a trade-off (negative association), and a $\mathrm{p}$-value between -0.6 and 0.6 is considered to indicate a non-classified.

\subsection{Prioritization of interlinkages for actions}

The proposed research involved a stakeholder survey in collecting feedback on the results of network analysis and regression analysis. It also aimed at prioritizing country actions based on the key stakeholders' perceptions and preferences. For this, an international workshop was organized on 25-26 June 2019 at Central University of Rajasthan, India. This workshop aimed to bring together and engage a wide range of stakeholders-government agencies, academic and research communities, civil societies, NGOs, international organizations and young professionals - on a common platform. Participants were divided into three groups with respect to SDG-2, SDG-6 and SDG-7 to prioritize and rank the top three targets from each goal based on their importance, status and national development strategies and priorities. After the group work, all three groups provided their final priorities and ranking of targets. A matrix was prepared for the prioritized targets and their correlation values (from the previous section) and further refined in priority based on the correlation values (Table 1).

The analysis provides a shortlist of indicators, which are measurable and fully reflect the proposed relevant targets as well as interdependent nature among the approved water, food and energy goals. Consequently, this list of indicators can help to manage water, food and energy effectively and meet related SDG targets more rapidly. 


\begin{tabular}{|l|l|}
\hline P-value & Priority level \\
\hline$>0.9$ & High \\
\hline $0.6-0.8$ & Moderate \\
\hline$<0.6$ & Low \\
\hline
\end{tabular}

TABLE 1. Matrix to prioritize interlinkages of targets.

\section{RESULTS AND DISCUSSION}

3.1 Stakeholder perception on interdependency of SDG targets on food, water and energy security

Figure 2 (a) shows the stakeholder perception on the dependency of SDG-2 on targets of SDG-6 and SDG-7. According to the results of the questionnaire survey, stakeholders believe that the achievement of SDG-2 is highly dependent on the three water security-related targets (T6.1, T6.3 and T6.4) with the highest weightage value of 2.63. Stakeholders' perception shows that energy security-related targets do not have a significant effect on SDG-2.

Figure 2 (b) shows the dependency of SDG-6 on targets of SDG-2 and SDG-7. Width of the lines indicates the strength of dependency. Stakeholders' perception results show a strong dependency of SDG- 6 on various targets of two other goals, including T2.1, T2.4, T2.2, and T7.1. The result implies that the implementation of SDG-6 should be integrated with different targets of SDG-2 and SDG-7.

In case of the dependency of SDG-7 on targets of SDG-2 and SDG- 6, the stakeholders' perception indicates that energy security is also highly dependent on various water targets including T6.3, T6.4 and T6.1 (refer to Figure 2 (c)).

The stakeholders' perception, as mentioned above, indicates that stakeholders believe there is an interdependency of water, energy and food security. The next section will determine whether and to what extent one target quantitatively correlates with the others.

\subsection{Quantitative assessment of interlinkages among the SDG targets on water, energy and food security}

The quantitative relationship among different targets has been examined to understand synergy or trade-off relationships among SDG-2, SDG-6 and SDG-7 targets which provide useful insight to identify priority interlinkages. Linkages among the three SDGs were analysed through pairwise correlation among the indicators measuring these targets. Pairwise correlation describes the direction of linkages between two variables. The interaction between target pairs of SDGs was split into three categories: synergy, trade-off and non-classified. For the Pearson's correlation, a p-value greater than 0.6 is considered to indicate a synergy (positive association) between two indicators, a p-value less than -0.6 is considered to indicate a trade-off (negative association), and a p-value between -0.6 and 0.6 is considered to indicate a non-classified.

The pairwise correlation coefficients with their statistical significance level are shown in Table 2 . The p-value ranges from -0.87 to +1.0 . Out of 182 (a) SDG-2 on targets of SDG-6 and SDG-7

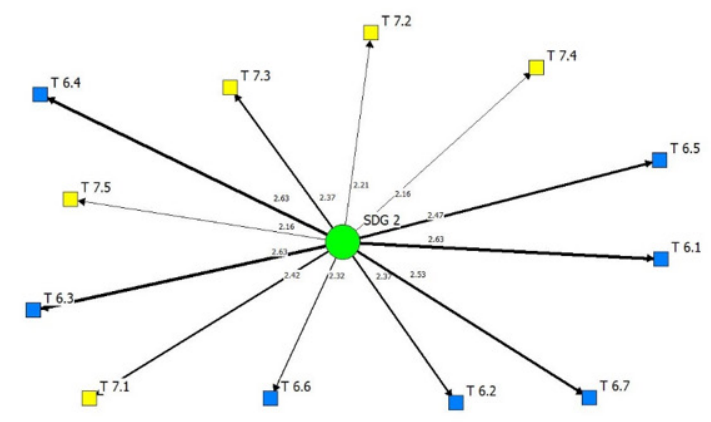

(b) SDG-6 on targets of SDG-2 and SDG-7

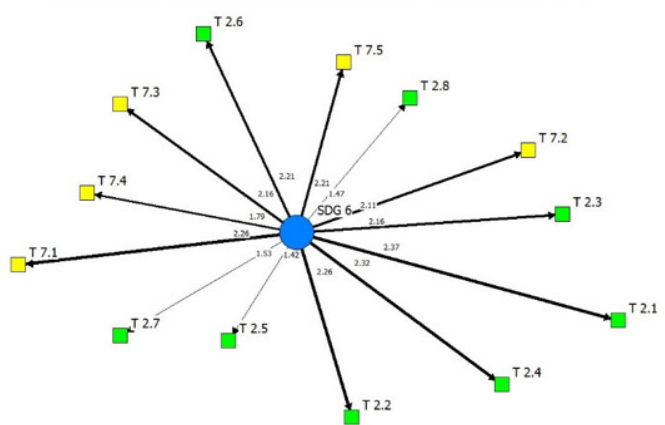

(c) SDG-7 on targets of SDG-2 and SDG-6

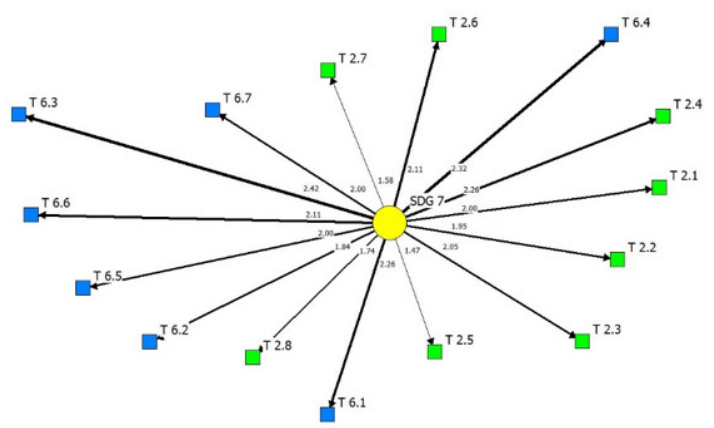

FIGURE 2. Visualisation of stakeholders' perceptions on the dependency of SDGs of food, water and energy on targets of other goals. 


\begin{tabular}{|c|c|c|c|c|c|c|c|c|c|c|c|c|c|c|}
\hline & T2.1 & $\mathrm{T} 2.2$ & T2.3 & T2.4 & T2.5 & T2.a & T6.1 & T6.2 & T6.3 & T6.6 & T6.a & T7.1 & $\mathrm{T} 7.2$ & T7.3 \\
\hline T2.1 & 1.000 & $.785 * *$ & $.740 * *$ & -0.137 & $.879 * *$ & $.698 * *$ & $.787 * *$ & $.790 * *$ & $.974 * *$ & $.944 * *$ & $.713 * *$ & $.730 * *$ & $.730 * *$ & $.719 * *$ \\
\hline T2.2 & $.785 * *$ & 1.000 & $.720 * *$ & 0.094 & $.899 * *$ & $.863^{* *}$ & -0.239 & $.996 * *$ & $.958 * *$ & $.936 * *$ & $.856 * *$ & $.940 * *$ & $.940 * *$ & $.713^{* *}$ \\
\hline T2.3 & $.740 * *$ & $.720 * *$ & 1.000 & -0.250 & $.799 * *$ & $.606 * *$ & -0.342 & $.679 * *$ & -0.184 & $.736 * *$ & $.662^{* *}$ & $.636 * *$ & $.636 * *$ & $.594 *$ \\
\hline T2.4 & -0.137 & 0.094 & -0.250 & 1.000 & 0.125 & 0.223 & -0.018 & 0.062 & 0.777 & -0.149 & -0.092 & 0.152 & 0.152 & 0.067 \\
\hline T2.5 & $.879 * *$ & $.899 * *$ & $.799 * *$ & 0.125 & 1.000 & $.850 * *$ & -0.158 & $.889 * *$ & 0.000 & $.922 * *$ & $.783 * *$ & $.826 * *$ & $.826 * *$ & $.569 *$ \\
\hline T2.a & $.698^{* *}$ & $.863^{* *}$ & $.606 * *$ & 0.223 & $.850 * *$ & 1.000 & -0.268 & $.864^{* *}$ & 0.767 & $.830 * *$ & $.740 * *$ & $.869 * *$ & $.869^{* *}$ & $.642^{* *}$ \\
\hline T6.1 & $.787 * *$ & -0.239 & -0.342 & -0.018 & -0.158 & -0.268 & 1.000 & $1.000 * *$ & -0.697 & -0.313 & -0.339 & -0.272 & -0.272 & $-.847^{* *}$ \\
\hline T6.2 & $.790 * *$ & $.996 * *$ & $.679 * *$ & 0.062 & $.889 * *$ & $.864 * *$ & $1.000^{* *}$ & 1.000 & $.969 * *$ & $.896 * *$ & $.842 * *$ & $.943 * *$ & $.943 * *$ & $.977^{* *}$ \\
\hline T6.3 & $.974 * *$ & $.958 * *$ & -0.184 & 0.777 & 0.000 & 0.767 & -0.697 & $.969 * *$ & 1.000 & 0.583 & 0.708 & 0.807 & 0.807 & 0.769 \\
\hline T6.6 & $.944 * *$ & $.936 * *$ & $.736 * *$ & -0.149 & $.922 * *$ & $.830 * *$ & -0.313 & $.896 * *$ & 0.583 & 1.000 & $.688^{*}$ & $.776 * *$ & $.776 * *$ & 0.524 \\
\hline T6.a & $.713 * *$ & $.856^{* *}$ & $.662^{* *}$ & -0.092 & $.783 * *$ & $.740 * *$ & -0.339 & $.842 * *$ & 0.708 & $.688^{*}$ & 1.000 & $.750 * *$ & $.750 * *$ & $.710 * *$ \\
\hline T7.1 & $.730 * *$ & $.940 * *$ & $.636 * *$ & 0.152 & $.826 * *$ & $.869 * *$ & -0.272 & $.943 * *$ & 0.807 & $.776 * *$ & $.750 * *$ & 1.000 & $1.000 * *$ & $.704 * *$ \\
\hline T7.2 & $.730 * *$ & $.940 * *$ & $.636 * *$ & 0.152 & $.826 * *$ & $.869 * *$ & -0.272 & $.943^{* *}$ & 0.807 & $.776 * *$ & $.750 * *$ & $1.000 * *$ & 1.000 & $.704 * *$ \\
\hline T7.3 & $.719 * *$ & $.713^{* *}$ & $.594 *$ & 0.067 & $.569 *$ & $.642 * *$ & $-.847^{* *}$ & $.977^{* *}$ & 0.769 & 0.524 & $.710 * *$ & $.704 * *$ & $.704 * *$ & 1.000 \\
\hline
\end{tabular}

TABLE 2. Pairwise Pearson's correlation among various targets (2000-2015). Statistical significance level of correlation coefficients have been presented in asterisks: $\mathrm{p}>0.6$ (synergies); $\mathrm{p}<-0.6$ (trade-off) and p -0.6 to 0.6 (non-classified). ${ }^{* *}$ Correlation is significant at the 0.01 level (2-tailed); *Correlation is significant at the 0.05 level (2-tailed).

interlinkages, 124 showed a synergistic relationship. This implies that there is a high potential to capture synergies by taking the nexus approach in SDGs implementation that can provide effective resource solutions and help to achieve three key SDGs. It is also important to identify trade-off interlinkages to manage the negative effect of one SDG target on other targets. In total, there are three interlinkages which displayed a trade-off relationship. It is unrealistic to suggest that any of the country studies incorporate all synergistic and trade-off interlinkages in the implementation of the SDGs. Therefore, it is important to prioritize interlinkages for immediate response, medium-term response and long-term response. The next section will prioritize the interlinkages for the country actions.

\subsection{Prioritization of interlinkages for actions}

Cross-sectoral group discussion prioritized the targets of each SDG based on certain justifications. Table 3 presents the prioritized targets of each SDGs with their possible justification. Some other linkages were revealed among the targets of each SDG, the awareness of which is important in order to implement plans and actions properly. This is considered necessary to achieve the targets and goals.

Based on the p-value in Table 2, a correlation matrix was prepared to classify the interlinked targets into different classes, i.e. high, moderate and low priority (Table 4). Interlinked targets with high priority are more important as there is high synergy, which can help in achieving goals more quickly and help address injudicious use of financial and natural resources. High priority interlinked targets are marked with three asterisks $(* * *)$, whereas a single asterisk $(*)$ indicates poorly correlated targets.

Target T2.2 is strongly correlated with other SDG targets like T6.2, T6.3, T7.2, T7.1. Similarly, target T6.2 is strongly correlated with all three energy targets. This means that there is a need to focus on these interlinked targets to accelerate the cumulative impact on water-energy-food security of the country.

\section{CONCLUSION}

Water, energy and food are basic elements for survival and essential for economic growth and sustainable development. Therefore, the importance of water, energy and food security has been well recognized in the approved SDGs, including SDG-2 (food), SDG-6 (water) and SDG-7 (energy). The world has been facing various challenges of security of these three resources; particularly, with Asia and the Pacific region taking the leading role in terms of economy and development. The continuing growth 


\begin{tabular}{|c|c|c|}
\hline Target & Target Description & Remark \\
\hline \multicolumn{3}{|c|}{$S D G-2$} \\
\hline $\mathrm{T}-2.4$ & $\begin{array}{l}\text { By } 2030 \text {, ensure sustainable food production systems and } \\
\text { implement resilient agricultural practices that increase } \\
\text { productivity and production. }\end{array}$ & $\begin{array}{l}\text { If production is not ensured, what should we make } \\
\text { available to eat? Identify food crops which are adapted } \\
\text { to the local climatic conditions and can also grow in } \\
\text { case of limited water or other resources. Conserve the } \\
\text { environment and natural resources. }\end{array}$ \\
\hline $\mathrm{T}-2.1$ & $\begin{array}{l}\text { By } 2030 \text {, end hunger and ensure universal access to nutritious } \\
\text { and sufficient food. }\end{array}$ & Food is essential for ensuring labour productivity. \\
\hline $\mathrm{T}-2.2$ & $\begin{array}{l}\text { By } 2030 \text {, end all forms of malnutrition, including achieving, } \\
\text { by } 2025 \text {, the internationally agreed targets on stunting and } \\
\text { wasting in children under five years of age. }\end{array}$ & To ensure a healthy population for future generations. \\
\hline \multicolumn{3}{|c|}{ SDG-6 } \\
\hline $\mathrm{T}-6.1$ & $\begin{array}{l}\text { By } 2030 \text {, achieve universal and equitable access to safe and } \\
\text { affordable drinking water for all. }\end{array}$ & $\begin{array}{l}\text { Consider the main priority to provide equitable access to } \\
\text { safe and affordable water for society's well-being and } \\
\text { good health. }\end{array}$ \\
\hline $\mathrm{T}-6.2$ & $\begin{array}{l}\text { By } 2030 \text {, achieve access to adequate and equitable sanitation } \\
\text { and hygiene for all and end open defecation, paying special } \\
\text { attention to the needs of women and girls and those in } \\
\text { vulnerable situations. }\end{array}$ & $\begin{array}{l}\text { To ensure a healthy population for future generations } \\
\text { and reduce society vulnerabilities. }\end{array}$ \\
\hline $\mathrm{T}-6.3$ & $\begin{array}{l}\text { By } 2030 \text {, improve water quality by reducing pollution, } \\
\text { eliminating dumping and the release of hazardous chemicals } \\
\text { and materials, halving the proportion of untreated } \\
\text { wastewater and substantially increasing recycling and safe } \\
\text { reuse globally. }\end{array}$ & $\begin{array}{l}\text { Improved water quality is a concern as it will help in the } \\
\text { protection of freshwater resources and the use of treated } \\
\text { wastewater. }\end{array}$ \\
\hline \multicolumn{3}{|c|}{ SDG-7 } \\
\hline $\mathrm{T}-7.2$ & $\begin{array}{l}\text { Increase the share of renewable energy in the global energy } \\
\text { mix substantially by } 2030 \text {. }\end{array}$ & $\begin{array}{l}\text { To improve the status of other targets, it is important to } \\
\text { have more sources of renewable energy. }\end{array}$ \\
\hline $\mathrm{T}-7.1$ & $\begin{array}{l}\text { By } 2030 \text {, ensure universal access to affordable, reliable, and } \\
\text { modern energy services. }\end{array}$ & To ensure the overall development of society. \\
\hline $\mathrm{T}-7.3$ & $\begin{array}{l}\text { Double the global rate of improvement in energy efficiency by } \\
2030 \text {. }\end{array}$ & $\begin{array}{l}\text { To ensure proper use and saving of energy with reduced } \\
\text { wastage. }\end{array}$ \\
\hline
\end{tabular}

TABLE 3. List of prioritized targets with their justification (from group discussion).

\begin{tabular}{llllllllll}
\hline & $\mathrm{T} 2.4$ & $\mathrm{~T} 2.1$ & $\mathrm{~T} 2.2$ & $\mathrm{~T} 6.1$ & $\mathrm{~T} 6.2$ & $\mathrm{~T} 6.3$ & $\mathrm{~T} 7.2$ & $\mathrm{~T} 7.1$ & $\mathrm{~T} 7.3$ \\
\hline $\mathrm{T} 2.4$ & - & - & - & $-0.081^{*}$ & $0.062^{*}$ & $0.77^{* *}$ & $0.15^{*}$ & $0.15^{*}$ & $0.07^{*}$ \\
$\mathrm{~T} 2.1$ & - & - & - & $0.79^{* *}$ & $0.79^{* *}$ & $0.97^{* * *}$ & $0.73^{* *}$ & $0.73^{* *}$ & $0.71^{* *}$ \\
$\mathrm{~T} 2.2$ & - & - & - & -0.23 & $0.99^{* * *}$ & $0.96^{* * *}$ & $0.94^{* * *}$ & $0.94^{* * *}$ & $0.71^{* *}$ \\
$\mathrm{~T} 6.1$ & - & - & - & - & - & - & $-0.27^{*}$ & $-0.27^{*}$ & $-0.84^{*}$ \\
$\mathrm{~T} 6.2$ & - & - & - & - & - & - & $0.94^{* * *}$ & $0.94^{* * *}$ & $0.97^{* * *}$ \\
$\mathrm{~T} 6.3$ & - & - & - & - & - & - & $0.80^{* *}$ & $0.80^{* *}$ & $0.76^{* *}$ \\
$\mathrm{~T} 7.2$ & - & - & - & - & - & - & - & - & - \\
$\mathrm{T} 7.1$ & - & - & - & - & - & - & - & - & - \\
$\mathrm{T} 7.3$ & - & - & - & - & - & - & - & - & - \\
\hline
\end{tabular}

TABLE 4. Pairwise Pearson's correlation among prioritised targets. *** High priority (>0.9);

** Moderate priority (0.6-0.8); * Low priority $(<0.6)$.

cannot achieve them. Hence, an integrated approach is required, and a water-energy-food nexus approach can provide an entry point to capture and utilize potential synergies in the implementation of SDG-2, SDG-6 and SDG-7 collectively. An integrated strategic planning process for capturing synergies and minimizing trade-offs in priority interlinkages in population will place immense pressures on these resources, which will lead to increasing conflicts unless integrated planning and decision-making framework are incorporated in development pathways. Stakeholders' cognition derived through scrutinizing the perception survey revealed essential aspects to incorporate nexus aspects in the action plans towards the SDGs. In the case of India, quantitative assessment of interdependency showed that, out of 182 interlinkages between targets of SDG-2, SDG-6 and SDG-7, 124 interlinkages have synergistic relation. Since the SDGs are interdependent, under the business-as-usual approach, the country among the goals and associated targets would help India to achieve co-benefits and strengthen institutional coordination for mainstreaming coordinated actions on SDGs (e.g. NITI-Aayog and Ministry of Finance of India can lead the process). In order to create a foundation for integrated strategic planning on SDGs, a capacity building programme for policy- and decision-makers is needed to provide a better understanding of interlinkages across the SDG goals and targets. Introducing incentive-based budget allocation mechanisms will recognize and emphasize cross-sectoral planning and coordinated 
actions on priority interlinkages.

\section{ACKNOWLEDGEMENT}

We want to thank the Asia-Pacific Network for Global Change Research (APN) for providing generous funding to support this research. Special thanks to Dr Linda Anne Stevenson, Ms Dyota Condrorini and Ms Nafesa Ismail, who provided detailed guidance and various support throughout the implementation of the project. We extend our sincere gratitude to them and to the many stakeholders who attended the stakeholder consultation workshops and to those who provided valuable comments and feedback.

\section{REFERENCES}

Bazilian, M., Rogner, H., Howells, M., Hermann, S., Arent, D., Gielen, D., ... Yumkella, K. K. (2011). Considering the energy, water and food nexus: Towards an integrated modelling approach. Energy Policy, 39(12), 7896-7906. doi:10.1016/j.enpol.2011.09.039

Merrey, D. (2015). Critical roles of water in achieving the proposed SDGs: A nexus perspective. Presented at the Workshop on "Capacity Development in Advancing Water and Sustainable Development", United Nations, New York City, NY. 24-25 February, 2015.

FAO, IFAD, UNICEF, WFP, \& WHO. (2017). The state of food security and nutrition in the world 2017: Building resilience for peace and food security. FAO, Rome. Retrieved from http://www.fao.org/3/a-i7695e.pdf

FAO, IFAD, UNICEF, WFP, \& WHO. (2019). The state of food security and nutrition in the world 2019: Safeguarding against economic slowdowns and downturns. Rome, FAO. Retrieved from http://www.fao.org/3/ca5162en/ ca5162en.pdf

Gallagher, L., Dalton, J., Bréthaut, C., Allan, T., Bellfield, H., Crilly, D., ... Vuille, F. (2016). The critical role of risk in setting directions for water, food and energy policy and research. Current Opinion in Environmental Sustainability, 23, 12-16. doi:10.1016/j. cosust.2016.10.002

Hauke, J., \& Kossowski, T. (2011). Comparison of values of Pearson's and Spearman's correlation coefficients on the same sets of data. Quaestiones Geographicae, 30(2), 87-93. doi:10.2478/v10117-011-0021-1

Hoff, H. (2011). Understanding the nexus: Background paper for the Bonn2011 Conference: The Water, Energy and Food Security Nexus. Stockholm Environment Institute, Stockholm.

ICIMOD. (2015). Contribution of Himalayan ecosystems to water, energy, and food security in South Asia: A nexus approach. Kathmandu: International Centre for Integrated Mountain Development (ICIMOD).
Retrieved from http://lib.icimod.org/record/1898/ files/nexus1.pdf

IEA. (2017). World Energy Outlook 2017. IEA Publications. Retrieved from https://www.iea.org/Textbase/ npsum/weo2017SUM.pdf

IEA. (2018). World Energy Outlook 2018. IEA Publications. Retrieved from https://webstore.iea.org/ world-energy-outlook-2018

Kuyama, T., Mitra, B. K., Pham, N. B, Sharma, D, Islam, G. M.T., \& Thao, P.T.M.(2019).Water-energy-food nexus perspective: Path making for Sustainable Development Goals (SDGs) to country actions in Asia. Technical Report. Retrieved from https://www.apn-gcr.org/ resources/files/original/624f571dad87d5a6c104c1e7ffdac580.pdf.

Rasul, G., \& Sharma, B. (2015). The nexus approach to water-energy-food security: an option for adaptation to climate change. Climate Policy, 16(6), 682-702. doi:10.1080/14693062.2015.1029865

Salam, P. A., Pandey, V. P., Shrestha, S., \& Anal, A. K. (2017). The need for the nexus approach. In P. A. Salam, S. Shrestha, V. P. Pandey, \& A. K. Anal (Eds.), Water-Energy-Food Nexus: Principles and Practices (pp. 1-10). Washington, DC: JohnWiley and Sons, Inc.

Scott C. A., Crootof, A., \& Kelly-Richards, S. (2016). The urban water-energy nexus: Building resilience for global change in the "urban century". In $\mathrm{H}$. Hettiarachchi \& R. Ardakanian (Eds.), Environmental Resource Management and the Nexus Approach: Managing Water, Soil, and Waste in the Context of Global Change (pp. 113-140). Berlin: Springer.

UNESCAP. (2019). Asia and the Pacific SDG Progress Report 2019. Retrieved from https://www.unescap.org/publications/ asia-and-pacific-sdg-progress-report-2019

Weitz, N., Nilsson, M., Huber-Lee, A., Davis, M., \& Hoff, H. (2014). Cross-sectoral integration in the Sustainable Development Goals: a nexus approach. SEI Discussion Brief. Retrieved from https://mediamanager.sei. org/documents/Publications/Air-land-waterresources/SEI-DB-2014-Nexus-SDGs-integration. pdf

WorldBank.(2018).Worlddevelopmentindicators. Retrieved August 18, 2018 from https://data.worldbank.org/ data-catalog/world-development-indicators

Waughray, D., \& Workman, J. G. (2011). Water security: The water-food-energy-climate nexus. The World Economic Forum Water Initiative. Washington D.C., USA: Island Press

WWAP. (2015). The United Nations world water development report 2015: Water for a sustainable world. Paris, UNESCO. 